\title{
O FOMENTO DE POSTURAS MAIS SUSTENTÁVEIS EM PROL DE ROBUSTECER O EQUILÍBRIO AMBIENTAL NO PARADIGMA HODIERNO
}

\author{
THE PROMOTION OF MORE SUSTAINABLE POSTURES IN ORDER TO \\ STRENGTHEN THE ENVIRONMENTAL BALANCE IN TODAY'S PARADIGM
}

\author{
Raquel Torres de Brito Silva ${ }^{1}$
}

\begin{abstract}
RESUMO
A sociedade de consumo contemporânea por muito tempo é influenciada por uma tática mercadológica utilizada pelo processo industrial evolutivo: o consumo. Embora necessário para a sobrevivência da humanidade e da satisfação dos anseios sociais, ele deve ser observado com cautela sob o seu aspecto de excesso/exagero, o que proporciona inexoravelmente um desrespeito aos parâmetros da sustentabilidade. A partir do momento que os desejos compulsivos dos consumidores se sobressaem ao respeito frente aos recursos naturais cada vez mais limitados, presenciamos uma crise ambiental (projetada na nossa conjuntura societária hodierna). Pelo exposto, necessária se faz a adoção de práticas mais sustentáveis em prol de robustecer o equilíbrio ambiental nos moldes instituídos pela nossa Constituição Verde. Dessa forma, o artigo visará tecer reflexões que justifiquem a necessidade de ampliar a conscientização ambiental nesse paradigma exposto. Utilizou-se o método dedutivo-qualitativo na elaboração da pesquisa, com bibliografias doutrinárias nacionais e estrangeiras.
\end{abstract}

PALAVRAS-CHAVE: Meio ambiente; Reflexões; Crise Ambiental.

\begin{abstract}
The contemporary consumer society for a long time is influenced by a marketing tactic used by the evolutionary industrial process: consumption. Although necessary for the survival of humanity and the satisfaction of social desires, it must be observed with caution under its aspect of excess/exaggeration, which inexorably provides a disrespect to the parameters of sustainability. From the moment that the compulsive desires of consumers stand out in the face of increasingly limited natural resources, we witness an environmental crisis (projected in our current social situation). For the above reasons, it is necessary

\footnotetext{
1 Mestranda em Direito pela Universidade Federal de Sergipe (UFS), São Cristóvão-SE, Brasil. Área de Concentração do Mestrado: Constitucionalização do Direito. Linha de Pesquisa: Eficácia dos direitos fundamentais e seus reflexos nas relações sociais e empresariais. Pós-graduanda (lato sensu) em Advocacia Pública pela Universidade Cândido Mendes (UCAM), Rio de Janeiro-RJ, Brasil. Bacharel em Direito pela Faculdade de Administração e Negócios de Sergipe (FANESE), AracajuSE, Brasil. Advogada pela Ordem dos Advogados do Brasil (OAB), Aracaju-SE, Brasil. E-mail: raqueltorres.95@hotmail.com
} 
SILVA, Raquel Torres de Brito. O fomento de posturas mais sustentáveis em prol de robustecer o equilíbrio ambiental no paradigma hodierno. Revista Eletrônica Direito e Política, Programa de PósGraduação Stricto Sensu em Ciência Jurídica da UNIVALI, Itajaí, v.14, n.2, 20 quadrimestre de 2019. Disponível em: www.univali.br/direitoepolitica - ISSN 1980-7791

to adopt more sustainable practices in order to strengthen the environmental balance in the ways established by our Green Constitution. Thus, the article will aim to make reflections that justify the need to expand environmental awareness in this paradigm exposed. The deductive-qualitative method was used in the preparation of the research, with national and foreign doctrinal bibliographies.

KEYWORDS: Environment; Reflections; Crisis Environmental.

\section{INTRODUÇÃO}

Um fato notório no paradigma contemporâneo é o constante desrespeito da relação do ser humano com o meio ambiente, sobretudo caracterizado pelas explorações dos seus recursos naturais cada vez mais limitados em prol da satisfação das necessidades antropológicas em demasia.

Neste diapasão, na medida em que

Desde os primórdios a relação do ser humano com a natureza tem sido utilitarista, no sentindo de que, para satisfazer suas necessidades, haveria de extrair recursos do ambiente, gerando, com isso, efeitos que inicialmente eram totalmente assimilados pelo ecossistema. ${ }^{2}$

Nesses moldes, são crescentes as mazelas socioambientais que podem ser notadas cotidianamente. Como exemplo observam-se a formação crescente dos resíduos sólidos, a contaminação dos lençóis freáticos, os desmatamentos em forte escala, o desgaste da camada de ozônio, o aumento do efeito estufa, as grandes perdas de biodiversidade, dentre outras consequências.

No que tange a essas três últimas mazelas, elas constituem

três questões que explicitam o cerne dos conflitos sociais sobre a sustentabilidade. Este cerne reside na dificuldade de, preservar e expandir as liberdades substantivas de que as pessoas hoje desfrutam sem comprometer a capacidade das

\footnotetext{
2 COSTA, Sandro Luiz da. Gestão integrada de Resíduos Sólidos Urbanos: aspectos jurídicos e ambientais. $1^{\circ}$ edição. Aracaju: Editora Evocati, 2011, p. 13.
} 
SILVA, Raquel Torres de Brito. O fomento de posturas mais sustentáveis em prol de robustecer o equilíbrio ambiental no paradigma hodierno. Revista Eletrônica Direito e Política, Programa de PósGraduação Stricto Sensu em Ciência Jurídica da UNIVALI, Itajaí, v.14, n.2, ${ }^{\circ}$ quadrimestre de 2019. Disponível em: www.univali.br/direitoepolitica - ISSN 1980-7791

futuras gerações desfrutarem de liberdade semelhante ou maior. ${ }^{3}$

Esses problemas já muito acentuados nos impulsionam a refletir que uma mudança de hábitos, precipuamente mais "sustentáveis", frente ao impulso do consumismo exacerbado, é imprescindível. Afinal,

As necessidades dos homens são ilimitadas, e os bens são limitados. Contraditoriamente, enquanto satisfazem certas necessidades, os bens estimulam outras. Para distinguir o homem dos demais animais, a fórmula mais satisfatória é dizer que o homem nunca está contente. Quanto mais tem, mais quer ter. ${ }^{4}$

Nesse toar, a proposta constitucional brasileira, elencada no artigo 225 da Lei Suprema de 1988, visando elevar à qualidade de "direito fundamental" o direito ao meio ambiente ecologicamente equilibrado, sugere um novo paradigma: o da sustentabilidade ambiental.

Para atingir efetivamente tal pretensão, deve ser elencada a necessidade de práticas mais sustentáveis e da ampliação de uma conscientização ambiental quanto aos efeitos do consumo excessivo e do robustecimento do equilíbrio ecológico.

Sob a forte influência do industrialismo e do mercado ansiando pela expansão econômica por meio das crescentes vendas, em prol de gerar lucro e rotatividade mercadológica, o consumo é impulsionado de sobremaneira.

Nesta ambiência, qual é o principal problema advindo do consumo contemporâneo? Sobre quais aspectos se baseia a necessidade pela adoção de hábitos e de práticas mais sustentáveis na atual conjuntura societária?

Essas questões menores, norteadoras do artigo, buscarão especificamente apontar o consumo exacerbado como principal precursor da crise ambiental contemporânea e, posteriormente, pretender-se-á analisar que a adoção por posturas mais sustentáveis é imprescindível para uma melhoria do paradigma

3 VEIGA, José Eli da. Desenvolvimento sustentável: o desafio do século XXI. Rio de janeiro: Garamond, 2010, p. 146.

${ }^{4}$ CARNELUTTI, Francesco. Como nasce o direito. São Paulo: Editora Pillares, 2015, p. 32. 
SILVA, Raquel Torres de Brito. O fomento de posturas mais sustentáveis em prol de robustecer o equilíbrio ambiental no paradigma hodierno. Revista Eletrônica Direito e Política, Programa de PósGraduação Stricto Sensu em Ciência Jurídica da UNIVALI, Itajaí, v.14, n.2, 20 quadrimestre de 2019. Disponível em: www.univali.br/direitoepolitica - ISSN 1980-7791

atualmente vivenciado, de modo a robustecer a relevância de respeitar-se o direito fundamental do meio ambiente sadio, equilibrado e digno.

Nesse aspecto, nos deparamos com a seguinte questão problema: Como a conscientização ambiental e a adoção de posturas mais sustentáveis podem robustecer o equilíbrio ambiental na conjuntura societária contemporânea?

Logo, em prol desses elencados dizeres, o objetivo cerne da pesquisa consiste em tecer apontamos que impulsionem a reflexão pela necessidade de ampliar-se a conscientização ambiental, preponderando pela adoção de hábitos mais sustentáveis em prol de respeitarmos o equilíbrio ambiental.

Pelo posto, a presente pesquisa visará ampliar as devidas reflexões em torno do tema em prol de influenciar a comunidade acadêmica e os leitores das diversas áreas, bem como a sociedade de um modo geral, demonstrando sua relevância jurídico-social na medida em que todos nós temos o dever intergeracional de respeitarmos o direito fundamental em baila e fazermos nossa parte em prol do equilíbrio ambiental.

Na elaboração do artigo foi utilizado o método dedutivo, de natureza qualitativa, utilizando-se de algumas pesquisas baseadas em doutrinas nacionais e estrangeiras, e em artigos referentes ao tema. Nesses moldes, "adotar-se-á, ainda, a técnica de pesquisa bibliográfica, a qual abrange as etapas de pesquisas, seleção, leitura e exame do material bibliográfico encontrado $[\ldots]^{\prime \prime}{ }^{5}$

\section{OS REFLEXOS DO CONSUMO HODIERNO EXACERBADO}

Dentre o extenso rol de direitos fundamentais previstos na Constituição Suprema de 1988, encontra-se o direito fundamental a um meio ambiente ecologicamente equilibrado, com previsão em seu artigo $225{ }^{6}$

\footnotetext{
5 MORAES, Kamila Guimarães de. Obsolescência planejada e direito: (in)sustentabilidade do consumo à produção de resíduos. Porto Alegre: Livraria do Advogado, 2015, p. 19.

6 BRASIL. Constituição (1988). Constituição da República Federativa do Brasil: texto constitucional promulgado em 05 de outubro de 1988. Brasília, DF: Senado Federal: Centro Gráfico, 1988.
} 
SILVA, Raquel Torres de Brito. O fomento de posturas mais sustentáveis em prol de robustecer o equilíbrio ambiental no paradigma hodierno. Revista Eletrônica Direito e Política, Programa de PósGraduação Stricto Sensu em Ciência Jurídica da UNIVALI, Itajaí, v.14, n.2, $2^{\circ}$ quadrimestre de 2019. Disponível em: www.univali.br/direitoepolitica - ISSN 1980-7791

Tamanha a sua relevância prática que percebemos que "é a proteção ao meio ambiente uma condição essencial para o livre desenvolvimento das potencialidades do indivíduo e para a melhoria da convivência social". ${ }^{7}$

Tendo em vista que a vida humana é marcada essencialmente por fortes mazelas ambientais, resta-nos aqui ponderar algumas considerações do seu principal motivo, analisando-o com base no paradigma hodierno.

Preliminarmente, importante se faz tecer breves comentários no que tange a sociedade industrial, a qual "havia arraigado na consciência coletiva do mundo a ideia de que o objetivo civilizatório consistia na constante ampliação do consumo per capita". ${ }^{8}$

Sob a influência incontestável do industrialismo, com suas plúrimas táticas de mercado, o desrespeito crescente da relação antropológica frente a natureza é gritante. Como resultado dessas preocupações ambientalistas, surge o evento do RIO 92, o qual "se constituiu verdadeiramente através de duas iniciativas complementares: A Conferência das Nações Unidas sobre Meio Ambiente e Desenvolvimento Sustentável $[\ldots]$ e o Fórum Global $[\ldots]^{\prime \prime}{ }^{9}$

Desta forma conforme as lições do autor, a convocação dessa Conferência se deu por força dos resultados do denominado "Relatório Nosso Futuro Comum", que foi síntese da Comissão Brundtland, a qual teria sido constituída com o fim de avaliação dos resultados da Conferência de Estocolmo (1972), na qual marcou a tomada de consciência da dimensão planetária dos problemas ambientais, cuja manifestação já se tornava evidente.

Tendo em vista a contribuição dos preceitos industrialistas, impactando o mundo com suas táticas de mercado, a exemplo do lançamento de produtos cada vez mais obsoletos, conforme será ponderado posteriormente, vivemos hoje em uma

\footnotetext{
7 JÚNIOR, Dirley da Cunha. Curso de direito constitucional. $8^{a}$ Ed. Salvador: editora JusPODIVM, 2014, p. 599.

8 BUARQUE, Cristovam. 0 colapso da modernidade brasileira e uma proposta alternativa; com a colaboração de Aldo Paviani [et al.]. Rio de Janeiro: Paz e Terra, 1991, p. 120.

9 TRIGUEIRO, André (org); SILVA, Marina. Meio ambiente no século 21: 21 especialistas falam de questões ambientais nas suas áreas de conhecimento. 5 ed. São Paulo: Armazém do Ipê, 2008, p. 143.
} 
SILVA, Raquel Torres de Brito. O fomento de posturas mais sustentáveis em prol de robustecer o equilíbrio ambiental no paradigma hodierno. Revista Eletrônica Direito e Política, Programa de PósGraduação Stricto Sensu em Ciência Jurídica da UNIVALI, Itajaí, v.14, n.2, $2^{\circ}$ quadrimestre de 2019. Disponível em: www.univali.br/direitoepolitica - ISSN 1980-7791

sociedade de "pós-modernidade", a qual se refere "a um deslocamento das tentativas de fundamentar a epistemologia, e da fé no progresso planejado humanamente". Essa condição da pós-modernidade é ainda "caracterizada por uma evaporação da grand narrative- o "enredo" dominante por meio do qual somos inseridos na história como seres tendo passado definitivo e um futuro predizível". ${ }^{10}$

Dessa forma, já dizia Bauman"11 que "a pós-modernidade é um lugar de oportunidades e também de perigo- e ambas as coisas pelas mesmas razões".

Todavia, apesar de ponderar-se acerca de alguns pontos evolutivos trazidos pela desenvoltura moderna, a sociedade não pode se cegar aos riscos disso advindos.

Pelo exposto, observam-se exemplificativamente o risco derivado do meio ambiente criado, ou da natureza socializada; o desenvolvimento de riscos ambientais institucionalizados no qual afeta a vida de milhões de pessoas; consciência do risco como risco; a consciência bem distribuída do risco e a consciência das limitações da perícia.

Logo, notar-se-á que um dos principais riscos advindos da expansão industrial, e do desenvolvimento societário moderno, é o capitalismo inovador. Afinal, "a natureza fortemente competitiva e expansionista do empreendimento capitalista implica que a inovação tecnológica tende a ser constante e difusa". ${ }^{12}$

No que tange ao processo econômico visado pelas indústrias, observa-se que esta detém duas zonas: a de produção e a de consumo. Na zona de consumo "tudo acaba e se destrói", na zona de produção "tudo começa e recomeça. Uma sociedade", escreveu Marx, "não pode parar de produzir, tal como não pode parar de consumir". ${ }^{13}$

\footnotetext{
10 GIDDENS, Anthony. As consequências da modernidade. São Paulo: Unesp, 1991, p. 12.

11 BAUMAN, Zygmunt. Modernidade e ambivalência. Tradução: Marcus Penchel. Rio de Janeiro: Jorge Zahar Ed., 1999, p. 277-278.

12 GIDDENS, Anthony. As consequências da modernidade. p. 68.

13 BRAUDEL, Fernand. Civilização material, economia e capitalismo: séculos XV-XVIII. São Paulo: Martins Fontes, 1996, p. 11.
} 
SILVA, Raquel Torres de Brito. O fomento de posturas mais sustentáveis em prol de robustecer o equilíbrio ambiental no paradigma hodierno. Revista Eletrônica Direito e Política, Programa de PósGraduação Stricto Sensu em Ciência Jurídica da UNIVALI, Itajaí, v.14, n.2, $2^{\circ}$ quadrimestre de 2019. Disponível em: www.univali.br/direitoepolitica - ISSN 1980-7791

Dessa forma, importante se faz explanar algumas considerações no que tange a uma das principais consequências dos avanços industriais mercadológicos: o consumo excessivo.

O consumo é uma caracterização do processo econômico industrial, difundindo, inexoravelmente, materiais das amplas tecnologias maquinárias. Nota-se que "o impacto do industrialismo é claramente não limitado à esfera de produção, mas afeta muitos aspectos da vida cotidiana, bem como influencia o caráter genérico da interação humana com o meio ambiente material". ${ }^{14}$

Consoante lições de Bauman ${ }^{15}$, o consumo, "a cobiçada liberdade do consumidor, é, afinal, o direito de escolher "por vontade própria" um propósito e um estilo de vida que a mecânica supra-individual do mercado já definiu e determinou para o consumidor".

Em certos aspectos o consumo é essencial para o ser humano satisfazer suas reais necessidades cotidianas, como na compra de alimentos, roupas, remédios, moradia, dentre outros anseios sociais indispensáveis a sobrevivência individual e convivência social.

Destarte, o que deve ser pauta de reflexões é se somos consumidores conscientes ou não dos devidos limites/freios frente as explorações dos recursos naturais em prol de satisfazer anseios "supérfluos" - como o excesso de compras de roupas, sapatos e casacos de couro ou não, relógios em demasia, bolsas e demais produtos que exigem muito dos recursos naturais e que, para alguns, são comprados em excesso em prol de um status a manter-, cegando-se, com isso, as mazelas provenientes da exploração da natureza em prol de atender tais pretensões.

Afinal,

Consumir, seja para fins de satisfação de "necessidades básicas" e/ou "supérfluas" - duas categorias básicas de entendimento da atividade de consumo nas sociedades

${ }^{14}$ GIDDENS, Anthony. As consequências da modernidade. p. 88.

15 BAUMAN, Zygmunt. Modernidade e ambivalência. p. 276-277. 
SILVA, Raquel Torres de Brito. O fomento de posturas mais sustentáveis em prol de robustecer o equilíbrio ambiental no paradigma hodierno. Revista Eletrônica Direito e Política, Programa de PósGraduação Stricto Sensu em Ciência Jurídica da UNIVALI, Itajaí, v.14, n.2, 20 quadrimestre de 2019. Disponível em: www.univali.br/direitoepolitica - ISSN 1980-7791

ocidentais contemporâneas- é uma atividade presente em toda e qualquer sociedade humana. ${ }^{16}$

Quanto às facetas do consumo, são relevantes as lições de Trigueiro, na medida em que

De um lado, o consumo abre enormes oportunidades para o atendimento de necessidades individuais de alimentação, habitação, saneamento, instrução, energia, enfim, de bemestar material, objetivando que as pessoas possam gozar de dignidade, auto-estima, respeito e outros valores fundamentais. ${ }^{17}$

Contudo, por outro lado,

O consumo distanciou-se do real, ou seja, dos bens necessários para a satisfação das necessidades; avançou-se, assim, para se tornar uma verdadeira usina de satisfação de desejos que induzem e criam necessidades para os consumidores, ou seja, são desejos manipulados, provocados pelos fornecedores sob uma perspectiva baseada na abundância e no crescimento econômico. ${ }^{18}$

Nesta ambiência, o consumo pregado pela expansão mercadológica- pelo enfoque das táticas industriais de vendas (como o marketing, o modismo midiático)- acaba abarcando um forte impacto, sobretudo socioambientalmente falando: a crise ambiental hodierna planetária.

Incube-se destacar aqui que o problema em baila não é o consumo em si mesmo, mas no que tange aos seus padrões e efeitos, no que se refere à conciliação de suas pressões ambientais e o atendimento das necessidades básicas da humanidade. A crítica consiste no consumo quando praticado em demasia e sem freios éticos sustentáveis.

\footnotetext{
16 BARBOSA, Livia. Sociedade de consumo. Rio de Janeiro: Zahar, 2004, p. 7.

17 TRIGUEIRO, André (org); SILVA, Marina. Meio ambiente no século 21: 21 especialistas falam de questões ambientais nas suas áreas de conhecimento, p. 148.

18 FRANZOLIN , Cláudio José. Obsolescência planejada e pós-consumo e a tutela do consumidor. Revista de Direito do Consumidor, Brasília, vol. 109, jan. - fev. 2017. Disponível em <file:///C:/Users/94316368591.CSM/Downloads/rt_periodical_92900151.pdf-.pdf >. Acesso em: 09 abr. 2017, não paginado.
} 
SILVA, Raquel Torres de Brito. O fomento de posturas mais sustentáveis em prol de robustecer o equilíbrio ambiental no paradigma hodierno. Revista Eletrônica Direito e Política, Programa de PósGraduação Stricto Sensu em Ciência Jurídica da UNIVALI, Itajaí, v.14, n.2, $2^{\circ}$ quadrimestre de 2019. Disponível em: www.univali.br/direitoepolitica - ISSN 1980-7791

Esse consumo em excesso reflete na alienação societária em extrapolar os limites do meio ambiente e dos seus recursos, ignorando as consequências nefastas provenientes disso.

Consoante aduz Bauman, "[...] todos os caminhos para a felicidade sugeridos passavam por lojas, restaurantes, salões de massagem e outros locais em que se pode gastar dinheiro"19. Aqui caracteriza-se a chamada "sociedade de consumo".

Conforme ensina Portilho, "a ideia de uma 'Sociedade de Consumo' vai além da ideia trivial de que todos os membros dessa sociedade consomem, uma vez que todos os seres humanos e todas as criaturas vivas consomem e sempre consumiram". 20

Corroborando com essa questão, Bauman salienta, quanto ao consumo em excesso, a notoriedade que "a fraqueza endêmica da satisfação instantânea e o vínculo próximo entre a obsessão pelo prazer instantâneo, a indiferença pelo que se foi e a desconfiança pelo que virá tendem a ser confirmados hoje $[\ldots]^{\prime \prime} .^{21}$

Neste cipoal, o consumo, quando exagerado e alienável frente à sociedade de consumidores, proporciona um verdadeiro "mundo de fantasia", no qual seus habitantes estão cientes de que "nunca terão o bastante, ou, na verdade, um volume suficiente de coisas bastante boas para estarem a salvo. O consumo não leva à certeza e à saciedade. O bastante nunca bastará".22

Mormente o que fora até então explicado, esse consumo, quando exacerbado, aumenta o poder de produção e da troca de mercadorias (obsoletas), repercutindo na formação de uma sociedade atual sem freios morais e eticamente sustentáveis.

Como uma das principais táticas mercantis, impulsionando o crescimento do consumismo excessivo, dominando a sociedade de consumo, e propiciando fortes

19 BAUMAN, Zygmunt. A arte da vida. Tradução: Carlos Alberto Medeiros. Rio de Janeiro. Jorge Zahar Ed., 2009, p. 34

20 PORTILHO, Fátima. Sustentabilidade ambiental, consumo e cidadania. São Paulo: Cortez, 2005, p. 74.

21 BAUMAN, Zygmunt. A sociedade individualizada: vidas contadas e histórias vividas. Tradução: José Gradel. Rio de Janeiro: Jorge Zahar Ed., 2008, p. 194-195.

22 BAUMAN, Zygmunt. A arte da vida. p. 35 
SILVA, Raquel Torres de Brito. O fomento de posturas mais sustentáveis em prol de robustecer o equilíbrio ambiental no paradigma hodierno. Revista Eletrônica Direito e Política, Programa de PósGraduação Stricto Sensu em Ciência Jurídica da UNIVALI, Itajaí, v.14, n.2, 20 quadrimestre de 2019. Disponível em: www.univali.br/direitoepolitica - ISSN 1980-7791

danos socioambientais, têm-se a tática obsoleta da formação dos produtos comercializados.

Nesta trilha, ensina-nos Trigueiro que:

$\mathrm{Na}$ disputa por mercado, no começo do século, a General Motors introduziu a obsolescência planejada, ao permitir que o consumidor pudesse escolher a cor do seu automóvel e mudar ano a ano o modelo. Nesse instante, o automóvel deixou de ser meio de transporte, passando a criar e atender a outras demandas, amparado como status e afirmação social, enfim, transformou-se em objeto de poder, amparado pela indústria da publicidade. ${ }^{23}$

Logo, a tática da formação de produtos obsoletos, programados para serem trocados de forma célere- seja pela funcionalidade ultrapassada, pelo desejo pelos novos produtos lançados, pela alienação inculcada- busca "atingir a felicidade", que "significa a aquisição de coisas que outras pessoas não têm chance nem perspectiva de adquirir". ${ }^{24}$

Aquisições de produtos virou um sinônimo de felicidade nessa sociedade atual. No entanto, "convirá notar que o nosso poder de nocividade e destruição ultrapassa largamente a nossa capacidade de construir". ${ }^{25}$

Os produtos obsoletos, em um primeiro momento, impulsionam o desejo por suas aquisições da forma mais célere possível e em demasia. Todavia, esses objetos lançados se tornam ultrapassáveis rapidamente e deixados de lado sem até mesmo oportunizarem seu aproveitamento concreto da melhor forma possível.

Afinal, "estilos de vida que hoje são chiques, amanhã se tornarão alvos de ridicularizarão"26. Éis o poder da obsolescência em termos sucintos.

Portanto, em prol de um viés conclusivo ante o exposto nesse primeiro momento, convém relembrarmos que "paradoxalmente, [....] o mundo mudou tanto para

\footnotetext{
23 TRIGUEIRO, André (org); SILVA, Marina. Meio ambiente no século 21: 21 especialistas falam de questões ambientais nas suas áreas de conhecimento. p. 150.

24 BAUMAN, Zygmunt. A arte da vida. p. 36.

25 BOURG, Dominique. Natureza e técnica: ensaio sobre a ideia de progresso. Lisboa: Instituto PIAGET, 1997, p. 106.

26 BAUMAN, Zygmunt. A sociedade individualizada: vidas contadas e histórias vividas. p. 197.
} 
SILVA, Raquel Torres de Brito. O fomento de posturas mais sustentáveis em prol de robustecer o equilíbrio ambiental no paradigma hodierno. Revista Eletrônica Direito e Política, Programa de PósGraduação Stricto Sensu em Ciência Jurídica da UNIVALI, Itajaí, v.14, n.2, 20 quadrimestre de 2019. Disponível em: www.univali.br/direitoepolitica - ISSN 1980-7791

melhor como para pior: de um lado trazendo conforto, de outro deteriorando o meio ambiente". ${ }^{27}$

$\mathrm{Na}$ medida em que o industrialismo trouxe inegáveis avanços econômicos, tecnológicos e confortáveis, ao mesmo tempo traz consigo táticas manipuladoras e produtos já programados para uma diminuição de sua vida útil.

Nesse aspecto reside o problema: o consumo é grande, a exploração frente aos recursos naturais é mais desrespeitada, e o socorro do meio ambiente é gritante.

Decerto que, para concretizar-se o direito fundamental ao meio ambiente ecologicamente equilibrado, fruto da constitucionalização do direito, é necessário sopesar nossos atuais hábitos de consumo em prol de mudá-los para atitudes mais "sustentáveis" e conscientes.

Nesse toar,

A constitucionalização do direito ao meio ambiente ecologicamente equilibrado, pela Constituição Federal de 1988 , enquanto um direito essencial à sadia qualidade de vida de "todos", cuja proteção depende da atuação solidária do Poder Público e da coletividade, e a garantia de sua efetividade perpassa pelo implemento de inúmeras políticas públicas, trata-se de um corajoso e importante compromisso da sociedade brasileira, constitucionalmente assumido, e de cujo efetivo e real cumprimento depende a qualidade de vida, inclusive, das futuras gerações. ${ }^{28}$

Pelo exposto, incube-se ponderar a seguir alguns apontamentos sobre a relevância da adoção de tais práticas mais sustentáveis a serem robustecidas no paradigma hodierno em prol do equilíbrio ambiental.

\section{O ROBUSTECIMENTO DE PRÁTICAS MAIS SUSTENTÁVEIS}

\footnotetext{
27 SCARLATO, Francisco Capuano. PONTIN, Joel Arnaldo. cons. RODRIGUES, Sérgio de Almeida. Do nicho ao lixo: ambiente, sociedade e educação. São Paulo: Atual, 1992, p. 1.

28 PADILHA, Norma Sueli. O compromisso constitucional brasileiro com a sustentabilidade ambiental. XXIII Encontro Nacional do CONPEDI/UFSC. Disponível em: <http://www.publicadireito.com.br/artigos/?cod=152c97a9bb6f2aba>. Acesso em 30 mar. 2019, p. 2.
} 
SILVA, Raquel Torres de Brito. O fomento de posturas mais sustentáveis em prol de robustecer o equilíbrio ambiental no paradigma hodierno. Revista Eletrônica Direito e Política, Programa de PósGraduação Stricto Sensu em Ciência Jurídica da UNIVALI, Itajaí, v.14, n.2, ${ }^{\circ}$ quadrimestre de 2019. Disponível em: www.univali.br/direitoepolitica - ISSN 1980-7791

Como outrora observado, o consumo trazido pela força industrialista e ampliado pelas táticas mercantis de venda, visando o crescimento econômico e lucrativo das empresas, afeta consideravelmente o meio ambiente em que vivemos, resultando em um consumo exacerbado, que é pregado e influenciado por esse processo evolutivo, mas que acaba contribuindo na formação de uma crise ambiental preocupante.

Essa crise ambiental contemporânea nos impulsiona a repensarmos acerca de nossa relação com a natureza, refletindo em consideráveis mudanças, sendo que, "vários elementos têm incidido nessas mudanças. As crises ecológicas locais ou regionais têm sido um deles [...]. hoje em dia, a principal novidade é o caráter planetário da crise ambiental". 29

Adentro da importância do tema em comento, Trigueiro salienta que "a crise que vivemos, enquanto Humanidade, oferece uma oportunidade única de revisão dos valores por ela praticados em todos os momentos, desde os atos mais simples do cotidiano, nos quais o consumo se insere" ${ }^{\prime 30}$.

Dessa forma, pertinente se faz refletir sobre essa relação desrespeitosa e exploratória do homem frente à natureza, sendo que, mesmo com altos índices de consumo observados na sociedade atual, parece que "a infelicidade dos consumidores deriva do excesso e não da falta de escolha". ${ }^{31}$

A necessidade em repensarmos nossas condutas, e valorizar a importância de uma mudança de conjuntura, é indispensável. Afinal, essa crise ambiental contemporânea que observamos é fruto das ameaças ecológicas provenientes do consumo em excesso. Ameaças estas que "são o resultado de conhecimento socialmente organizado, mediado pelo impacto do industrialismo sobre o meio ambiente material". ${ }^{32}$

29 FOLADORI, Guillermo. Limites do desenvolvimento sustentável. Campinas: Editora da Unicamp, São Paulo: Imprensa Oficial, 2001, p. 136.

30 TRIGUEIRO, André (org); SILVA, Marina. Meio ambiente no século 21: 21 especialistas falam de questões ambientais nas suas áreas de conhecimento. p. 157.

31 BAUMAN, Zygmunt. Modernidade líquida. Tradução: Plínio Dentzien. Rio de Janeiro: Jorge Zahar, 2001, p. 75.

32 GIDDENS, Anthony. As consequências da modernidade. p. 122. 
SILVA, Raquel Torres de Brito. O fomento de posturas mais sustentáveis em prol de robustecer o equilíbrio ambiental no paradigma hodierno. Revista Eletrônica Direito e Política, Programa de PósGraduação Stricto Sensu em Ciência Jurídica da UNIVALI, Itajaí, v.14, n.2, $2^{\circ}$ quadrimestre de 2019. Disponível em: www.univali.br/direitoepolitica - ISSN 1980-7791

A necessidade de proteção ambiental é imprescindível. Afinal, nas palavras de Rodrigues, proteger o meio ambiente é "proteger o espaço, o lugar, o recinto, que abriga, que permite e que conserva todas as formas de vida" 33 .

Para tal viés protetivo, indispensável se faz traçar breves comentários sobre a adoção de práticas mais sustentáveis nesse paradigma contemporâneo analisado. Afinal, Veiga explica que a sustentabilidade ambiental "é baseada no duplo imperativo ético de solidariedade sincrônica com a geração atual e de solidariedade diacrônica com as gerações futuras". ${ }^{34}$ Há aqui um dever solidário e intergeracional para sua proteção.

Mormente a necessidade de mudanças, relevante se faz refletir sobre alguns consideráveis problemas ambientais e a necessidade pela adoção de novos hábitos, na medida em que o ser humano, ligado à natureza, dela depende para sua própria sobrevivência com qualidade, saúde e dignidade.

A própria ação humana já ameaça sua própria condição de sobrevivência, o obrigando a repensar suas condutas e reconhecer seus limites inerentes. Afinal, esta situação comentada deve ser vista sob o aspecto da oportunidade de revisões profundas "de valores, práticas e questionamentos da nossa imagem sobre nós mesmos, ainda que possamos nos sentir impotentes, frágeis e despreparados em função da magnitude da tarefa diante da qual estamos colocados". ${ }^{35}$

Uma relação mais respeitosa entre o ser humano e a natureza é a meta em prol de uma ruptura da crise contemplada. Vislumbra-se aqui a possibilidade de uma "sociedade sustentável", sendo esta compreendida como um "completo entendimento das formas mediante as quais o capital natural e o capital feito pelo homem - tecnologias, equipamentos, saber, ideias- são usados em combinação

\footnotetext{
33 RODRIGUES, Marcelo Abelha. Direito ambiental esquematizado. coordenação Pedro Lenza. 3. ed. São Paulo: Saraiva, 2016, p. 70.

34 VEIGA, José Eli da. Desenvolvimento sustentável: o desafio do século XXI. p. 171.

35 TRIGUEIRO, André (org); SILVA, Marina. Meio ambiente no século 21: 21 especialistas falam de questões ambientais nas suas áreas de conhecimento. p. 146-147.
} 
SILVA, Raquel Torres de Brito. O fomento de posturas mais sustentáveis em prol de robustecer o equilíbrio ambiental no paradigma hodierno. Revista Eletrônica Direito e Política, Programa de PósGraduação Stricto Sensu em Ciência Jurídica da UNIVALI, Itajaí, v.14, n.2, $2^{\circ}$ quadrimestre de 2019. Disponível em: www.univali.br/direitoepolitica - ISSN 1980-7791

para produzirem os bens e serviços que atende às necessidades e desejos humanos". ${ }^{36}$

Para fortalecer tal linha argumentativa, serão a seguir elencados alguns dos principais impactos ambientais, observados contemporaneamente, em prol de fomentar a necessidade do robustecimento do equilíbrio ambiental no paradigma moderno.

Como exemplos de tais mazelas, têm-se a radiação a partir de acidentes graves em usinas nucleares ou do lixo atômico; a poluição química nos mares suficientes para destruir o plâncton que renova uma boa parte do oxigênio na atmosfera; o "efeito estufa" derivando dos poluentes atmosféricos que atacam a camada de ozônio, derretendo partes das calotas polares e inundando vastas áreas; a destruição de grandes áreas de florestas tropicais que são uma fonte básica de oxigênio renovável; e a exaustão de milhões de acres de terra fértil como resultado do uso intensivo de fertilizantes artificiais.

Tendo em vista o contexto caótico observado, outros problemas notórios estariam atrelados à mortalidade infantil, a desarticulação do sistema educacional, a permanência de doenças endêmicas, o sucateamento da estrutura econômica, científica e tecnológica já montada, e a miséria crescente. Necessário se faz, portanto, ampliar e divulgas as sérias preocupações em torno da questão suscitada.

Com isso, "a expansão da consciência ambiental se dá na exata proporção em que percebemos meio ambiente como algo que começa dentro de cada um de nós, alcançando tudo o que nos cerca e as relações que estabelecemos com o universo". 37

Importante ponderar também que os trabalhos no que tange aos limites do "crescimento e seu impacto ecológico, a insatisfação com o consumismo, a

36 CLÓVIS, Cavalcanti (org.). Meio ambiente, desenvolvimento sustentável e políticas públicas. $4^{\circ}$ edição. São Paulo: Cortez: Recife: Fundação Joaquim Nabuco, 2002, p. 135.

37 TRIGUEIRO, André (org); SILVA, Marina. Meio ambiente no século 21: 21 especialistas falam de questões ambientais nas suas áreas de conhecimento. p. 13. 
SILVA, Raquel Torres de Brito. O fomento de posturas mais sustentáveis em prol de robustecer o equilíbrio ambiental no paradigma hodierno. Revista Eletrônica Direito e Política, Programa de PósGraduação Stricto Sensu em Ciência Jurídica da UNIVALI, Itajaí, v.14, n.2, $2^{\circ}$ quadrimestre de 2019. Disponível em: www.univali.br/direitoepolitica - ISSN 1980-7791

desigualdade intrínseca ao processo de industrialização [...] têm levantado dúvidas sobre o futuro da civilização industrial em suas atuais características". ${ }^{38}$

É preciso mostrar, em linhas concretas e efetivas, que o processo de crescimento econômico mercantil não pode continuar impune, principalmente tendo em vista que este viola as regras de respeito ambiental e prudência ecológica. ${ }^{39}$

Estabelecido o panorama da crise ambiental no contexto societário hodierno, consubstancia-se o entendimento atrelado à necessidade de repensarmos sobre nossas atuais práticas consumistas, em prol de sopesar com os notórios efeitos/consequências das constantes e reiteradas explorações aos recursos ambientais.

Assentes e inconcussas tais premissas, proteger a natureza e a exploração crescente dos seus recursos, possibilita-nos a formação de um meio ambiente mais digno, sadio e com qualidade de vida, que constitui um dever solidário de toda a comunidade.

Decerto que tal dever liga-nos, inexoravelmente, ao pacto intergeracional, oriundo da magnitude da questão, sendo, ademais, o direito fundamental ao meio ambiente um direito de terceira geração/dimensão, pertencendo a toda uma coletividade.

Esposando tal pensamento, Filho explana que os

Direitos de terceira geração (difusos e coletivos) São direitos transindividuais, isto é, direitos que são de várias pessoas, mas não pertencem a ninguém isoladamente. Transcendem o indivíduo isoladamente considerado. São também conhecidos como direitos metaindividuais (estão além do indivíduo) ou supraindividuais (estão acima do indivíduo isoladamente considerado) ${ }^{40}$

${ }^{38}$ BUARQUE, Cristovam. $\mathbf{O}$ colapso da modernidade brasileira e uma proposta alternativa. $\mathrm{p}$. 36.

39 CLÓVIS, Cavalcanti (org.). Meio ambiente, desenvolvimento sustentável e políticas públicas. p. 24.

40 FILHO, João trindade cavalcante. Teoria geral dos direitos fundamentais. Disponívelem:<https://www.stf.jus.br/repositorio/cms/portaltvjustica/portaltvjusticanoticia/anex 
SILVA, Raquel Torres de Brito. O fomento de posturas mais sustentáveis em prol de robustecer o equilíbrio ambiental no paradigma hodierno. Revista Eletrônica Direito e Política, Programa de PósGraduação Stricto Sensu em Ciência Jurídica da UNIVALI, Itajaí, v.14, n.2, $2^{\circ}$ quadrimestre de 2019. Disponível em: www.univali.br/direitoepolitica - ISSN 1980-7791

Pelo exposto, algumas medidas podem ser adotadas em prol de aprofundar tais reflexões, sobretudo quanto a crise ambiental contemporânea, como por exemplo, "se uma comunidade humana demonstra preferência pela conservação de determinado ecossistema em vez da implantação de um parque de diversões". ${ }^{41}$

A possibilidade de formação de uma Política de governo em prol da sustentabilidade também deve ser considerada, bem como maiores investimentos em políticas públicas ambientais.

Essa política de governo significa uma orientação das ações públicas motivadas "pelo reconhecimento da limitação ecológica fundamental dos recursos (matéria e energia, em última análise), sem os quais nenhuma atividade humana pode se realizar". 42

No que tange ainda a esta realidade degradante vivenciada, no qual abrange as falhas institucionais de solucionar os malefícios visíveis, necessário seria também buscar por um efetivo "controle social" em prol de modificar o contexto atual observado. 43

Nesse paradigma presenciado, é preciso "disciplina e controle para passear através das mercadorias em exposição, olhar e não agarrar, movimentar-se casualmente sem interromper o fluxo, contemplar com entusiasmo moderado [... $]^{\prime 44}$. Ou seja, necessário se faz uma mudança de hábitos/posturas pautados nos parâmetros da sustentabilidade. Dessa forma, possível será formar sociedades mais conscientes.

Assim sendo, para "o estabelecimento de comunidades saudáveis e inteligentes"45, é necessário para a formação de um novo paradigma.

o/joao_trindadade_teoria_geral_dos_direitos_fundamentais.pdf>. Acesso em: 30 mar. 2019, p. 13.

41 VEIGA, José Eli da. Desenvolvimento sustentável: o desafio do século XXI. p. 147.

42 CLÓVIS, Cavalcanti (org.). Meio ambiente, desenvolvimento sustentável e políticas públicas. p. 30.

43 MÉSZAROS, István. A crise estrutural do capital. São Paulo: Boitempo, 2011, p. 71.

44 FEATHERSTONE, Mike. Cultura de consumo e pós-modernismo. Tradução: Julio Assis Simões. São Paulo: Studio Nobel, 1995, p. 45.

45 TRIGUEIRO, André (org); SILVA, Marina. Meio ambiente no século 21: 21 especialistas falam de questões ambientais nas suas áreas de conhecimento. p. 31. 
SILVA, Raquel Torres de Brito. O fomento de posturas mais sustentáveis em prol de robustecer o equilíbrio ambiental no paradigma hodierno. Revista Eletrônica Direito e Política, Programa de PósGraduação Stricto Sensu em Ciência Jurídica da UNIVALI, Itajaí, v.14, n.2, $2^{\circ}$ quadrimestre de 2019. Disponível em: www.univali.br/direitoepolitica - ISSN 1980-7791

Este novo paradigma, portanto, pressupõe, inexoravelmente, um conjunto de posturas no viés dessa sustentabilidade: "estas podem ser sintetizadas no seguinte trinômio: eficiência econômica, eficácia social e ambiental. O cumprimento simultâneo desses requisitos significa atingir o desenvolvimento sustentável". ${ }^{46}$

A partir do momento que nos conscientizarmos a respeito das mazelas provenientes do consumo em excesso, e enxergarmos os fortes e gritantes impactos que atingem, imensuravelmente, o meio ambiente em que vivemos, será possível concretizar gradativamente, por meio do nosso dever intergeracional, a formação de um meio ambiente mais sadio e equilibrado para as presentes e futuras gerações. Para atingir tal intento, necessário se faz ponderar-se quanto as nossas atitudes corriqueiras como consumidores.

Dessa forma, "essa compreensão demonstra a essencialidade do meio ambiente ecologicamente equilibrado, direito de terceira dimensão, que se reveste em um dos mais significativos direitos fundamentais". ${ }^{47}$

\section{CONSIDERAÇÕES FINAIS}

Tendo em vista as razões fáticas expostas, o presente artigo buscou, como objetivo principal, tecer reflexões que justifiquem a necessidade pela expansão da consciência ambiental, preponderando-se a adoção de hábitos que sejam mais sustentáveis em prol de respeitarmos o direito fundamental ao meio ambiente ecologicamente equilibrado e sadio- tanto para as presentes, como para as gerações vindouras.

Dessa forma, em um primeiro momento, buscou-se aqui apontar que uma das principais decorrências do processo industrialista, que influencia inexoravelmente e em linhas incomensuráveis a sociedade atual, consiste no consumo.

\footnotetext{
46 FILHO, Gilberto Montibeller. O mito do desenvolvimento sustentável: Meio ambiente e custos sociais no moderno sistema produtor de mercadorias. Florianópolis: Ed. Da UFSC, 2004, p. 54.

47 OLIVEIRA, Fabiano Melo Gonçalves de. Direito ambiental. 2. ed. rev., atual. e ampl. Rio de Janeiro: Forense; São Paulo: MÉTODO, 2017, p. 82.
} 
SILVA, Raquel Torres de Brito. O fomento de posturas mais sustentáveis em prol de robustecer o equilíbrio ambiental no paradigma hodierno. Revista Eletrônica Direito e Política, Programa de PósGraduação Stricto Sensu em Ciência Jurídica da UNIVALI, Itajaí, v.14, n.2, $2^{\circ}$ quadrimestre de 2019. Disponível em: www.univali.br/direitoepolitica - ISSN 1980-7791

Todavia, frise-se que a crítica em comento não tange ao consumo em geral (imprescindível para a sobrevivência humanitária), mas sim quanto ao consumo exacerbado/exagerado, pregado pelo mercado através de táticas obsoletas/programas em prol de girar a máquina econômico-lucrativa de forma mais célere.

Nessa toada, o consumismo é um fator impulsionante para a gradativa formação de mazelas socioambientais provenientes do desrespeito humano frente à natureza e os seus recursos.

Neste diapasão, a título exemplificativo, no que tange a questão em comento, presenciamos altos índices de lixo atômico, resíduos sólidos formados de modo crescente, a poluição química nos mares e lençóis freáticos, o efeito estufa, a permanência de doenças endêmicas, o sucateamento da estrutura econômica, científica e tecnológica já montada, e a miséria crescente, destruição de grandes áreas de florestas tropicais, dentre outros impactos que merecem atenção tamanha sua gravidade.

Com tal linha intelectiva, tais problemas observados motivam o clamor do meio ambiente por mudanças e, sobretudo, por mais respeito. Decerto que, em prol disso, necessário se faz ampliar o víeis reflexivo em torno da questão por meio da adoção de práticas mais sustentáveis em prol da construção de um mundo melhor, sobretudo, visando-se o robustecimento do equilíbrio ambiental em prol de projetar-se uma vida mais saudável e digna.

Nessa esteira, estabelecidas as principais reflexões referentes ao tema em comento, notar-se-á que, a partir do momento que nos conscientizarmos persistentemente em torno dos pontos outrora debatidos, de modo a cumprirmos nosso dever intergeracional na construção de um meio ambiente ecologicamente equilibrado, sadio e digno para as gerações presentes e vindouras, e de maneira a adotarmos hábitos mais sustentáveis, possível será então, mormente a tais aspectos, uma ruptura gradativa desse paradigma ambientalmente caótico até então presenciado. 
SILVA, Raquel Torres de Brito. O fomento de posturas mais sustentáveis em prol de robustecer o equilíbrio ambiental no paradigma hodierno. Revista Eletrônica Direito e Política, Programa de PósGraduação Stricto Sensu em Ciência Jurídica da UNIVALI, Itajaí, v.14, n.2, $2^{\circ}$ quadrimestre de 2019. Disponível em: www.univali.br/direitoepolitica - ISSN 1980-7791

\section{REFERÊNCIA DAS FONTES CITADAS}

BARBOSA, Livia. Sociedade de consumo. Rio de Janeiro: Zahar, 2004.

BAUMAN, Zygmunt. A arte da vida. Tradução: Carlos Alberto Medeiros. Rio de Janeiro. Jorge Zahar Ed., 2009.

A sociedade individualizada: vidas contadas e histórias vividas. Tradução: José Gradel. Rio de Janeiro: Jorge Zahar Ed., 2008.

. Modernidade e ambivalência. Tradução: Marcus Penchel. Rio de Janeiro: Jorge Zahar Ed., 1999.

Zahar, 2001.

Modernidade líquida. Tradução: Plínio Dentzien. Rio de Janeiro: Jorge

BOURG, Dominique. Natureza e técnica: ensaio sobre a ideia de progresso. Lisboa: Instituto PIAGET , 1997.

BRASIL. Constituição (1988). Constituição da República Federativa do Brasil: texto constitucional promulgado em 05 de outubro de 1988. Brasília, DF: Senado Federal: Centro Gráfico, 1988.

BRAUDEL, Fernand. Civilização material, economia e capitalismo: séculos XVXVIII. São Paulo: Martins Fontes, 1996.

BUARQUE, Cristovam. 0 colapso da modernidade brasileira e uma proposta alternativa; com a colaboração de Aldo Paviani [et al.]. Rio de Janeiro: Paz e Terra, 1991.

CARNELUTTI, Francesco. Como nasce o direito. São Paulo: Editora Pillares, 2015.

CLÓVIS, Cavalcanti (org.). Meio ambiente, desenvolvimento sustentável e políticas públicas. $4^{\circ}$ edição. São Paulo: Cortez: Recife: Fundação Joaquim Nabuco, 2002.

COSTA, Sandro Luiz da. Gestão integrada de Resíduos Sólidos Urbanos: aspectos jurídicos e ambientais. $1^{\circ}$ edição. Aracaju: Editora Evocati, 2011.

FEATHERSTONE, Mike. Cultura de consumo e pós-modernismo. Tradução: Julio Assis Simões. São Paulo: Studio Nobel, 1995. - (Coleção cidade aberta. Série megalópolis).

FILHO, Gilberto Montibeller. 0 mito do desenvolvimento sustentável: Meio ambiente e custos sociais no moderno sistema produtor de mercadorias. Florianópolis: Ed. Da UFSC, 2004. 
SILVA, Raquel Torres de Brito. O fomento de posturas mais sustentáveis em prol de robustecer o equilíbrio ambiental no paradigma hodierno. Revista Eletrônica Direito e Política, Programa de PósGraduação Stricto Sensu em Ciência Jurídica da UNIVALI, Itajaí, v.14, n.2, $2^{\circ}$ quadrimestre de 2019. Disponível em: www.univali.br/direitoepolitica - ISSN 1980-7791

FILHO, João trindade cavalcante. Teoria geral dos direitos fundamentais. Disponívelem:<https://www.stf.jus.br/repositorio/cms/portaltvjustica/portaltvjus ticanoticia/anexo/joao_trindadade_teoria_geral_dos_direitos_fundamentais.pdf >. Acesso em: 30 mar. 2019.

FOLADORI, Guillermo. Limites do desenvolvimento sustentável. Campinas: Editora da Unicamp, São Paulo: Imprensa Oficial, 2001.

FRANZOLIN , Cláudio José. Obsolescência planejada e pós-consumo e a tutela do consumidor. Revista de Direito do Consumidor, Brasília, vol. 109, jan. - fev. 2017.

<file://C:/Users/94316368591.CSM/Downloads/rt_periodical_92900151.pdf.pdf >. Acesso em: 09 abr. 2017.

GIDDENS, Anthony. As consequências da modernidade. São Paulo: Unesp, 1991.

JÚNIOR, Dirley da Cunha. Curso de direito constitucional. $8^{a}$ Ed. Salvador: editora JusPODIVM, 2014.

MÉSZAROS, István. A crise estrutural do capital. São Paulo: Boitempo, 2011.

MORAES, Kamila Guimarães de. Obsolescência planejada e direito: (in)sustentabilidade do consumo à produção de resíduos. Porto Alegre: Livraria do Advogado, 2015.

OLIVEIRA, Fabiano Melo Gonçalves de. Direito ambiental. 2. ed. rev., atual. e ampl. Rio de Janeiro: Forense; São Paulo: MÉTODO, 2017.

PADILHA, Norma Sueli. O compromisso constitucional brasileiro com a sustentabilidade ambiental. XXIII Encontro Nacional do CONPEDI/UFSC. Disponível em: <http://www.publicadireito.com.br/artigos/?cod=152c97a9bb6f2aba >. Acesso em 30 mar. 2019.

PORTILHO, Fátima. Sustentabilidade ambiental, consumo e cidadania. São Paulo: Cortez, 2005.

RODRIGUES, Marcelo Abelha. Direito ambiental esquematizado. coordenação Pedro Lenza. 3. ed. São Paulo: Saraiva, 2016.

SCARLATO, Francisco Capuano. PONTIN, Joel Arnaldo. cons. RODRIGUES, Sérgio de Almeida. Do nicho ao lixo: ambiente, sociedade e educação. São Paulo: Atual, 1992.

TRIGUEIRO, André (org); SILVA, Marina. Meio ambiente no século 21: 21 especialistas falam de questões ambientais nas suas áreas de conhecimento. 5 ed. São Paulo: Armazém do Ipê, 2008. 
SILVA, Raquel Torres de Brito. O fomento de posturas mais sustentáveis em prol de robustecer o equilíbrio ambiental no paradigma hodierno. Revista Eletrônica Direito e Política, Programa de PósGraduação Stricto Sensu em Ciência Jurídica da UNIVALI, Itajaí, v.14, n.2, 20 quadrimestre de 2019. Disponível em: www.univali.br/direitoepolitica - ISSN 1980-7791

VEIGA, José Eli da. Desenvolvimento sustentável: o desafio do século XXI. Rio de janeiro: Garamond, 2010.

RECEBIDO EM: 19/06/2019

APROVADO EM: 25/07/2019 